\title{
Decoupling Capacitance Enabled Water Pumping System using Photovoltaic System
}

\author{
Kolli Srisai Sudhakar Reddy, P.Adithya Sesha Sai Krishna, Sk. Moulali, M.Naga Chaitanya
}

\begin{abstract}
A two-stage PV water-pumping system architecture is represented in this paper. In contrast with other alternatives available in the literature, the electronic drive does not exploit batteries to accomplish energy decoupling, neither large electrolytic capacitors in between stages. Although these two design decisions respectively minimize environmental impacts and increase the converter's expected lifetime, they also bring about considerable control difficulties. More specifically, the DC link stiffness is reduced and thus large voltage oscillations may occur. In order to overcome this problem, a nonlinear controller interconnection between the individual compensator of each stage is created to account for the low capacitance. Simulations and experimental results demonstrate the effectiveness of the method in stabilizing the DC-link voltage under sudden solar irradiation changes. The final converter was deployed in a remote rural community in Guinea-Bissau for crop irrigation purposes. Despite the harsh conditions such as high temperatures and sea breeze, in situ results were satisfactory and validated the system robustness
\end{abstract}

Keywords: PV water-pumping, electronic pump drive, interconnected control, decoupling capacitance.

\section{INTRODUCTION}

In Recent measurements on the populace circulation around the world demonstrate that urban regions [1] have gotten more involved than rustic ones in the most recent decades. In spite of the fact that this datum is significant, it just speaks to the normal incentive among all nations and consequently doesn't delineate the truth of individual countries. As instances of this reality, while country populace [3] represents under 13\% in Argentina, Australia and Brazil, it establishes over $62 \%$ in India, Vietnam and in the whole Sub-Saharan Africa. Breaking down the more specific instance of remote provincial communities[2][5], the

Manuscript published on November 30, 2019.

* Correspondence Author

Kolli Srisai Sudhakar Reddy *, B.Tech, Department of Electrical and Electronics Engineering, Koneru Lakshmaiah Education Foundation, Vaddeswaram, AP, India.. Email: sreddykolli2@gmail.com

P.Adithya Sesha Sai Krishna, B.Tech, Department of Electrical and Electronics Engineering, Koneru Lakshmaiah Education Foundation, Vaddeswaram, AP, India... Email: saikrishna.pas@gmail.com

Sk. Moulali, Department of Electrical and Electronics Engineering, Koneru Lakshmaiah Education Foundation, Vaddeswaram, AP, India. Email: itsmoulali212@kluniversity.in

M.Naga Chaitanya, Department of Electrical and Electronics Engineering, Koneru Lakshmaiah Education Foundation, Vaddeswaram, AP, India. Email: naga.6174@kluniversity.in

(C) The Authors. Published by Blue Eyes Intelligence Engineering and Sciences Publication (BEIESP). This is an open access article under the CC-BY-NC-ND license http://creativecommons.org/licenses/by-nc-nd/4.0/ nearness of geographic boundaries or even the absence of foundation in general regularly keep them from being associated with the primary electrical grid[14] of their own nation. This legitimately influences the prosperity of people because of the constructive relationship with power [18] accessibility particularly in creating locales. Also, confined little networks frequently experience the ill effects of shortage of clean water and inhabitants may need to make a trip long separation to arrive at the closest well. By giving water to either human utilization or harvest water system, sun based controlled water siphoning frameworks [4] assume a focal job in expanding the general personal satisfaction of those networks. The benefits of photovoltaic-based water-siphoning frameworks (PVPS) for remote locales over fuel-based siphons is that the previous doesn't create ozone harming substances and that, there are no common expenses during activity after the sun based boards are purchased and introduced. It is realized that some discussion exists about the effects caused the sun powered boards producing process, still they are viewed as a nature-accommodating [4] option in contrast to petroleum derivatives. From the application perspective, unpredictable sun oriented light because of overcast climate may end the framework for specific timeframes accordingly trading off water accessibility [9]. This issue can be handled by utilizing batteries as a subsequent vitality source or by building a raised tank, thus empowering evening water system for instance. Unmistakably, while settling on the first arrangement one needs to contemplate various elements to check the achievability of his battery framework: introductory cost, lifetime, upkeep cost, transfer cost, wellbeing and ecological effect. The second option then again requests increasingly physical space yet is amazingly more straightforward inside the setting of water system. DC engines were dominating in early PVPS frameworks presented during the 1970s. Since a solitary DC-DC converter is sufficient to drive such machines, low expenses and high efficiencies can be achieved, making this engineering as yet engaging when the ostensible power is low. All the more as of late, Kumar and Singh examined the reasonableness of brushless direct-ebb and flow engines to sun powered water-siphoning, inferring that the electronic hardware could be simplified, yet the control calculations also. By the by, AC engines are known to be rough, entirely dependable and require less upkeep as looked at their DC partners. These are genuinely basic perspectives, particularly if the framework is to be introduced in a difficult to-arrive at area or if there are no specialists at all to fix it from potential disappointments. 


\section{Decoupling Capacitance Enabled Water Pumping System using Photovoltaic System}

The utilization of squirrel-confine acceptance engines, open-end winding enlistment engines, changeless magnet synchronous engines, and exchanged hesitance engines [10] in PVPS was additionally examined by numerous scientists. Despite the utilized innovation, it is critical to ensure a final equal electric burden that works the photovoltaic [11] board cluster at its greatest power point.

In the most widely recognized greatest power point following [13] (MPPT) systems are assessed and looked at: annoy and watch [12], steady voltage (CV), gradual conductance (IC) and the $\beta$ technique. In this a two-arrange photovoltaic water-siphoning framework architecture for three-stage AC siphons is proposed1. Interestingly with different options present in the writing, the electronic drive doesn't abuse batteries to achieve vitality decoupling between control converters, in this manner limiting its natural effect. In addition, huge electrolytic capacitors are not utilized in the DC [14]-connect, yet just little film capacitors, which significantly increment the converter's normal lifetime. Be that as it may, the DC-interface voltage solidness is decreased and undesired motions may emerge. The primary hypothetical commitment of this work is to feature how to adapt to this issue by methods for a specific nonlinear interconnection of two separate controllers. This thusly improves the dynamic conduct of the converters when the PV boards are exposed to unexpected sun oriented illumination [20] changes. Recreations and test results are given as a proof of idea. A short portrayal of the elevated level finite state machine (FSM) that manages the framework conduct is likewise given. The PVPS was conveyed in a remote burdened network of 80 ranchers in Guinea-Bissau for the water system of roughly 850 harvest beds. In situ siphoning results show that, in spite of the brutal natural conditions, for example, high temperatures and the nearness of ocean breeze with salty air, the final electronic drive was physically powerful and its presentation was acceptable.

\section{SYSTEM OVER VIEW}

A schematic outline of the proposed PVPS is appeared in Figure-1. The primary hinders that create the framework are: Block 1: A PV array that can be organized in three diverse configurations: an exceptional string of two $240 \mathrm{~W}$ top boards in arrangement (480 W top all out), a parallel association of two recently depicted strings (970 $\mathrm{W}$ top all out), and a parallel association of three strings (1470 W top complete);

Block 2: A conservative two-organize electronic converter that actualizes a CV MPPT system and drives the acceptance engine with the V/f variable-recurrence strategy to maintain a strategic distance from attractive immersion of its core.

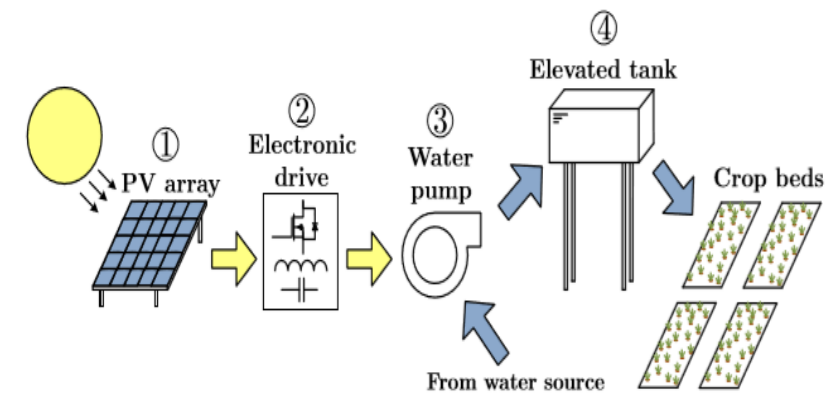

Figure-1:- Different types of blocks used in the paper.

Yellow colour arrows curresponds to theenergy path and blue colour arrows curresponds to the water flow
Block 3: A submersible water siphon 220 VRMS, $60 \mathrm{~Hz}$ three-stage enlistment engine, found 9.5 meters somewhere down in the water well;

Block 4: A 23 meters pressure driven circuit that conveys the siphoned water into a 15 meters tall raised repository, to be later utilized in crop water system.

Three variants of the electronic framework were planned: 500 $\mathrm{W}, 1 \mathrm{~kW}$ and a $1.5 \mathrm{~kW}$ rendition. The $1.5 \mathrm{~kW}$ model can drive engines of ostensible catalyst to $1.5 \mathrm{hp}$, the $1 \mathrm{~kW}$ model can deal with engines up to $1 \mathrm{hp}$, and the $500 \mathrm{~W}$ models is limited to machines up to $0.5 \mathrm{hp}$.

\section{POWER ELECTRONIC CONVERTER}

A circuit graph of the electronic drive framework is given in Figure-2, though data about every one of its segments is accounted for in Table I. The framework features a little info electrolytic capacitor Cin, in any case, this is a solitary part working under impressively low voltage stress.

A. DC-DC and DC-AC Stages A separated interleaved support converter in arrangement with a voltage doubler circuit is utilized as the information stage to rise the information voltage to $350 \mathrm{~V}$ level in the DC-interface. The exchanging recurrence for Q1 and Q2 is $60 \mathrm{kHz}$. The fundamental bit of leeway of this topology is its improved efficiency when contrasted with a customary lift while keeping up a low information current wave, which keeps the activity to go astray unnecessarily from the maximum or greatest power point (MPP). The transformer turns proportion is $1: 1.5$, along these lines causing a slight voltage increment, while likewise giving extra yields to control little cooling fans. The subsequent static addition for this configuration is:

Gain $=3 /(1-D), D \geqslant 0.5$. It is imperative to watch the limitation on the obligation cycle value $\mathrm{D}$, since one switch should consistently be shut to ensure a shut way for the inductors'

flows.

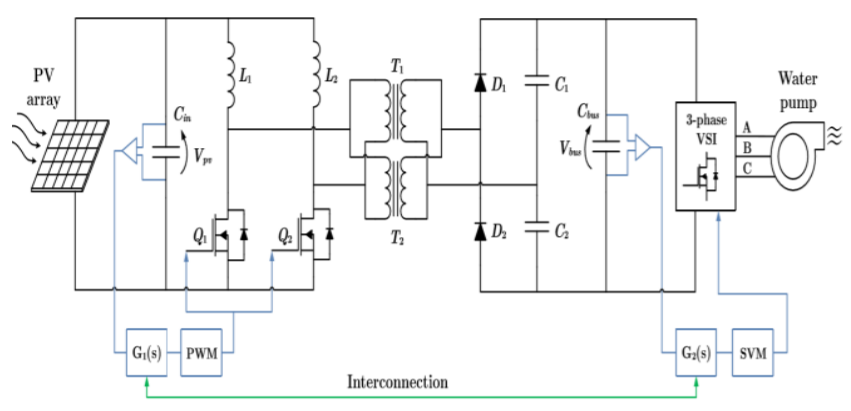

Figure-2:- Over view of the system used in this paper In this manner, a standard three-stage voltage source inverter changes over the DC to AC to drive the water-siphon enlistment engine at various velocities, contingent upon the accessible vitality. The space vector balance method was picked to make the essential PWM signals, while a V/f conspire ensures that the machine's attractive center isn't soaked.

The exchanging recurrence utilized for the semiconductors in this stage is $18 \mathrm{kHz}$ and, along these lines, next to no discernible clamor is delivered since it is at the farthest point of the human hearing reach. 
From the very circuit topology of Fig. 2, unmistakably the VSI switches are exposed to higher voltage stress when contrasted with the lift switches, while the previous need to endure higher flows.

No filter is utilized at the yield of the DC-AC organize in light of the fact that lone the yield flows should be sinusoidal to deliver a pivoting attractive filed in the machine's inside. As appeared in the exploratory outcomes, the stator windings inductances are now sufficient to smooth the current flow. In addition, if capacitors somehow happened to be utilized for filtering purposes, the wonder of self-excitation of enlistment engines could emerge, making water be siphoned when the framework should be out of commission.

\section{SYSTEM STATES AND CONTROL METHODOLOGY}

Singular Control Laws and Stabilizing Interconnection the factors picked to be controlled are the info voltage Vpv and the DC-interface voltage Vbus. Following the CV MPPT technique, directing Vpv to $80 \%$ of the PV exhibit open circuit voltage Voc guarantees that the framework working condition is near the MPP. Then again, keeping Vbus at a predefined fixed esteem ( $350 \mathrm{~V}$ for this situation) ensures that the SVM will to be sure produce the right sinusoidal sign required to drive the electric machine [10]. Both the obligation cycle to switches Q1 and Q2 and the recurrence $\mathrm{f}$ of stages $\mathrm{A}, \mathrm{B}$ and $\mathrm{C}$ are utilized as control factors. Note that an expansion of the obligation cycle D causes Vpv to diminish (first control circle). Thus, expanding the SVM recurrence $f$ that drives the engine builds the heap, causing Vbus to diminish (second control circle). The backwards proportionality of both control circles - i.e., an augmentation on a specific input prompts a decrement of the separate yield - will be later investigated in the interconnection stage.

\begin{tabular}{ll}
\hline Component & Specification \\
\hline$L_{1}, L_{2}$ & $\begin{array}{l}280 \mu \mathrm{H} \\
17 \times \mathrm{AWG} 25\end{array}$ \\
\hline$C_{1}, C_{2}$ & $\begin{array}{l}4.7 \mu \mathrm{F}, 450 \mathrm{~V} \\
\text { Film capacitor }\end{array}$ \\
\hline$C_{\text {in }}$ & $\begin{array}{l}220 \mu \mathrm{F}, 100 \mathrm{~V} \\
\text { Electrolytic capacitor }\end{array}$ \\
\hline$C_{\text {bus }}$ & $\begin{array}{l}3 \mu \mathrm{F}, 450 \mathrm{~V} \\
\text { Film capacitor }\end{array}$ \\
\hline$T_{1}, T_{2}$ & $\begin{array}{l}1: 1.5 \text { turns ratio } \\
6 \times \mathrm{AWG} 25\end{array}$ \\
\hline$D_{1}, D_{2}$ & $\begin{array}{l}V_{R}=600 \mathrm{~V}, I_{F}=25 \mathrm{~A} \\
\text { HFA25PB60 }\end{array}$ \\
\hline$Q_{1}, Q_{2}$ & $\begin{array}{l}V_{D S}=300 \mathrm{~V}, I_{D}=160 \mathrm{~A} \\
\text { IXFX160N30T }\end{array}$ \\
\hline 3-phase VSI & $\begin{array}{l}V_{D S}=900 \mathrm{~V}, I_{D}=36 \mathrm{~A} \\
\text { switches }\end{array}$ \\
\hline
\end{tabular}

Table-1:- Info regarding the components in Figure-2

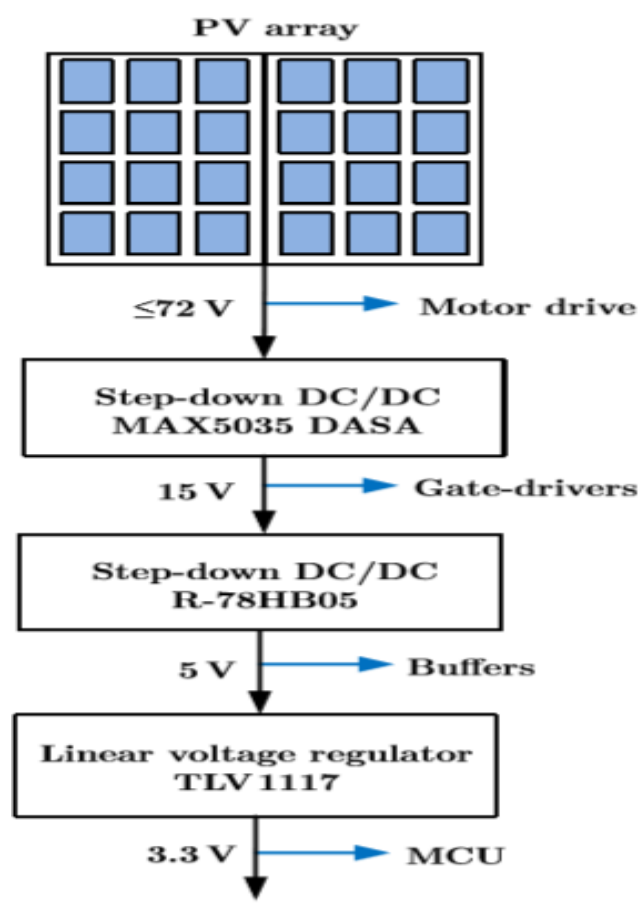

Figure-3:- Auxilary power supplies and available voltage levels.

Two particular relative indispensable (PI) controllers were independently intended for the previously mentioned first and second circles. The related exchange capacities are

$$
\mathrm{G} 1,2(\mathrm{~s})=\mathrm{Kp} 1,2+(\mathrm{Ki} 1,2 / \mathrm{s})
$$

Where Kp1 = 1, Ki1 = 5/(2^10),

$$
\mathrm{Kp} 2=1 \text { and } \mathrm{Ki} 2=50 /(2 \wedge 10) \text {. }
$$

The voltage sensors delineated in Fig. 2 apply extra gains of $\left(4.48 \cdot 10^{\wedge}-2\right)$ and $\left(5.57 \cdot 10^{\wedge}-3\right)$ to $\mathrm{G} 1(\mathrm{~s})$ and $\mathrm{G} 2(\mathrm{~s})$, individually. An advanced usage of the control laws was done on the MCU. The Vpv and Vbus signals were examined by the 10 bits ADC both at $306 \mathrm{~Hz}$ and their compensators were coded on a solitary intrude on administration schedule. Depending absolutely on the two PIs to deal with the total framework might be a feasible alternative if the capacitance Cbus is sufficiently high to decouple the two elements. See for instance the outcomes announced in [7] where MPP following and speed guideline were accomplished while utilizing a 2036 $\mu \mathrm{F}$ capacitor in the DC-interface. By the by, if Cbus is low, a little addition on the lift obligation cycle or even an unexpected change in the sunlight based irradiance delivers an extensive variety of Vbus, therefore influencing the yield of the subsequent circle. This cooperation between control stages makes the way toward tuning the four additions (Kp1, $\mathrm{Kp} 2$, Ki1 and Ki2) an extremely overwhelming and tedious undertaking. Besides, regardless of whether solidness is accomplished close to the balance condition, the absence of heartiness may make the framework shut-down when exposed to huge sunlight based light changes [20]. So as to beat these restrictions, G1(s) and G2(s) were interconnected as appeared in being $\mathrm{K}$ a steady of combination to be balanced, and $\operatorname{sat}(\cdot)$ a capacity that soaks its contention if fundamental either at the mediocre furthest reaches of 0 or at the unrivaled furthest reaches of 0.2 .

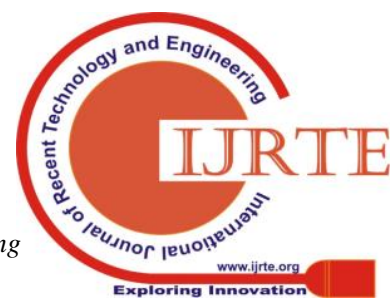




\section{Decoupling Capacitance Enabled Water Pumping System using Photovoltaic System}

The articulation inside the furthest enclosure of (3) speaks to the voltage file utilized in the CV MPPT calculation. Henceforth, the picture of $g(\bullet)$ is the reference sign to the first control circle. At whatever point the recurrence is expanded due to Vbus > $350 \mathrm{~V}$, the yield of G2(s) can build the reference for $\mathrm{G} 1(\mathrm{~s})$ through $\mathrm{g}(\bullet)$, balancing out the DC connect. Likewise, if $\mathrm{Vpv}$ is higher than its reference, the obligation cycle is expanded causing Vbus to increment as a reaction. Because of the subsequent interconnection appeared in Fig. 4, the recurrence is additionally expanded, lessening Vbus.

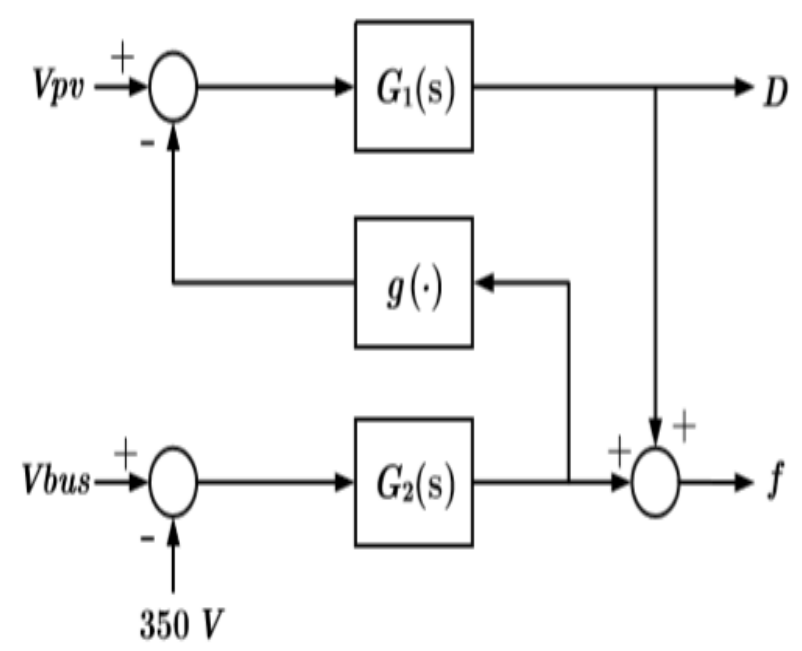

Figure-4: Interconnection of the two control loops

Roughly speaking, and the summation square of yields in can be viewed as feed-forward terms between elements. Rather than trusting that the reactions will be corrupted and the criticism ways to address the deviations regarding the references, the proposed interconnection acts all the more quickly if $\mathrm{K}$ is appropriately picked. By and by, figuring the essential comes down to playing out a gathering with greatest and least qualities individually of 0.2 and 0 .

\section{DECOUPLING CAPACITOR}

This is a capacitor which can decouple any part of the electrical [18] network from the other. It can reduce the noise that is caused by the other elements in the circuit, and it reduces the effect it has on the remaining circuit. It has an alternative name called as a Bypass capacitor as it can bypass the power supply of the circuit or the higher impedance of the circuit.

This is often used for decoupling a sub circuit from Ac signals on the power supply or the other line. It can be a shunt energy from those signals which the sub-circuit to be decoupled right to the return path. Another kind decoupling is stopping a portion of circuit which is been affected by the switching that occurs in the other portion of the circuit. These may not be alone sufficient in case of high power amplifier stage with low pre amplifier coupled to it.

\section{EXPERIMENTAL RESULTS}

Mat lab Simulink Model

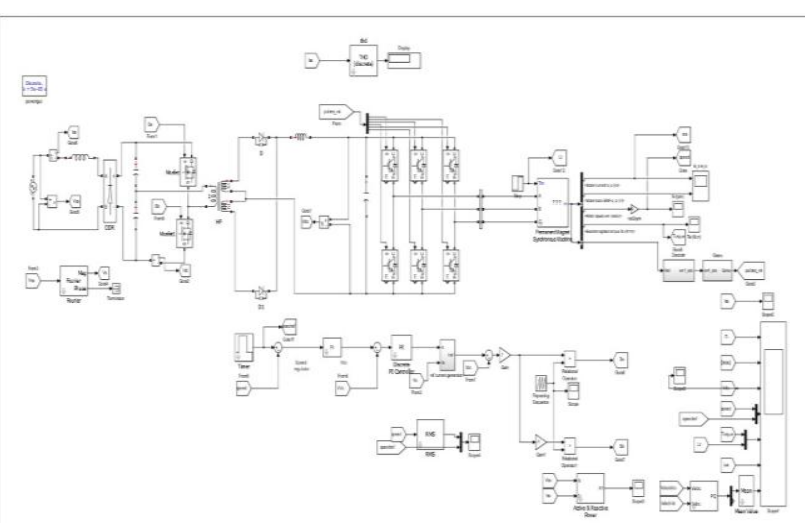

Figure-5:- The matlab Simulink diagram figure-5 showing all the connections and the outputs are verified.

Results:

Rotor Speed

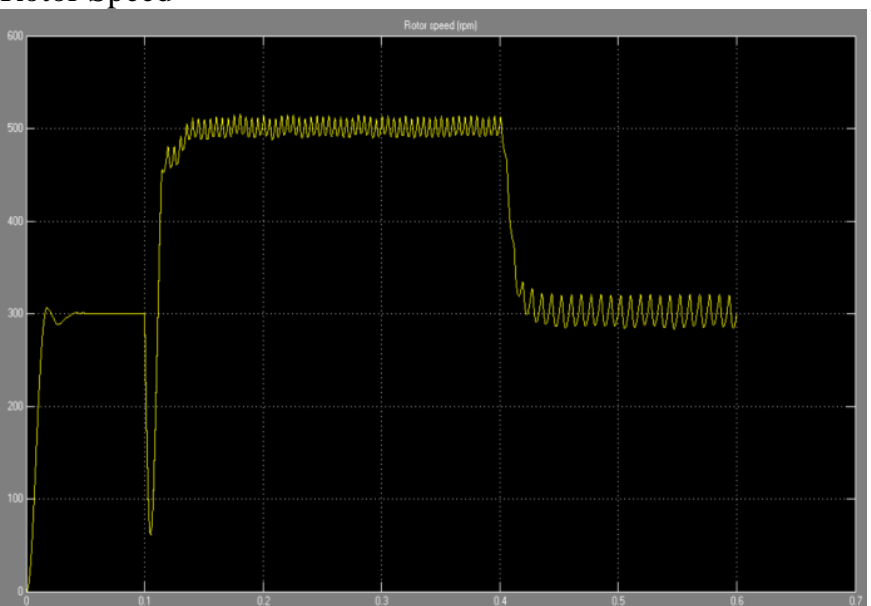

Figure-6:- This figure-6 the rotor speed of the BLDC motor [19] used in the above diagram and it represents the speed of the machine.

Stator Current and stator back EMF

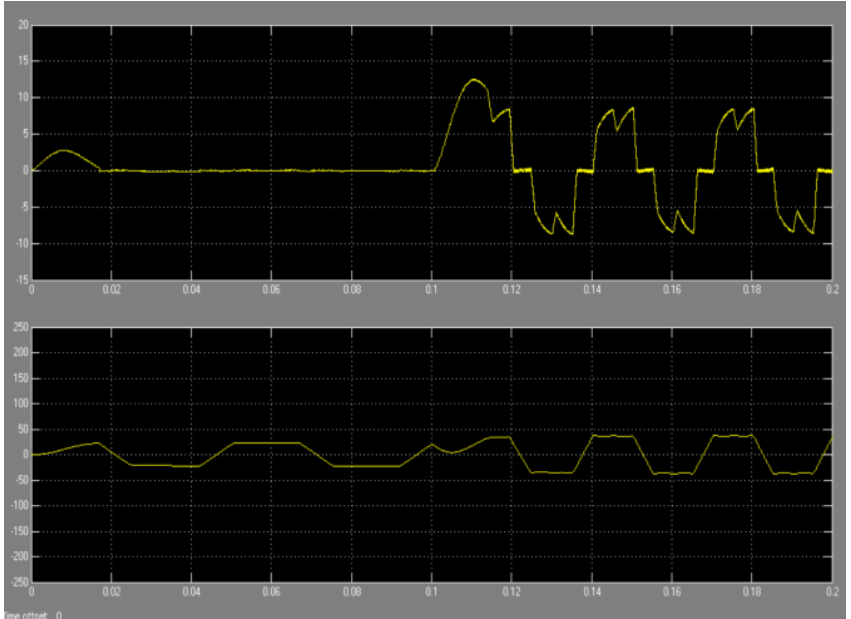

Figure-7:- This figure-7 the stator current and stator back emf. The current of the stator raised to 5 and then became 0 up to $0.1 \mathrm{sec}$. But that current is sufficient to rum a motor up to $0.1 \mathrm{sec}$ and that's why the stator current is 0 up to $0.1 \mathrm{~s}$

Electromagentic Torque 


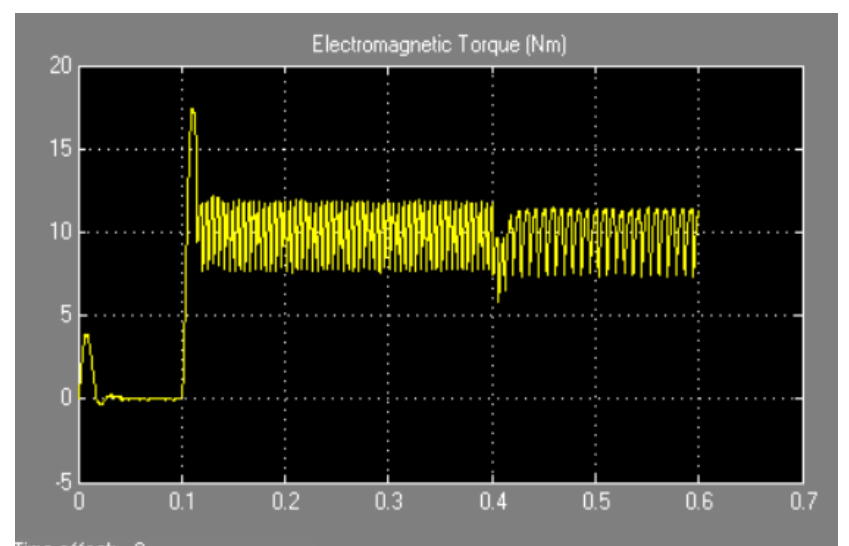

Figure-8: - The figure-8 represents the electromagnetic torque and this torque is produced when the motor runs.

Voltage, current, vdc, speed, torque, iaa, mean value

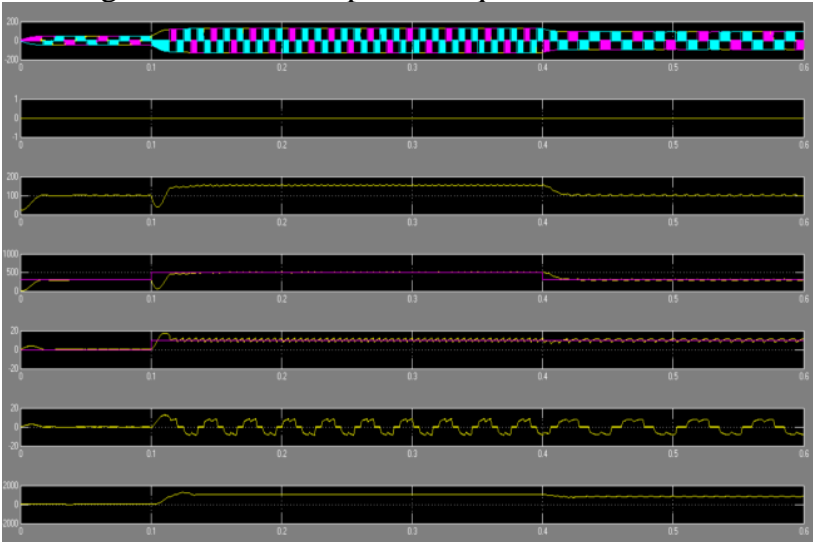

Figure-9:- This Figure-9 represents all the voltage, current, vdc, speed, torque, iaa, mean value. All the wave forms are taken in a single scope such that the variations can be found and it can be seen through the scopes.

\section{CONCLUSIONS AND FUTURE WORKS}

An epic PVPS architect for AC pumps was proposed in this work, including no batteries for vitality decoupling and just small film capacitors in the DC-connect link. Structure choices were made considering both cost decrease and heartiness in perspective on the cruel conditions in which the electronic drive would be introduced. The equipment is made out of a stage up arrange and a voltage-source inverter, though the control from the equipment perspective, future works incorporate investigating elective DC-DC converter topologies so as to lessen the transient voltage tops during fire up. Likewise, by determining a scientific model of the entire framework - from the PV cluster to the water siphon - the level of coupling between stages could be all the more absolutely estimated. One of the accessible measurements to gauge such an amount is the relative increase cluster (RGA), which would require a linearization of the whole multivariable elements around some specific balance point. It is normal that the less approximations are utilized in the modelling stage, the more precise the coupling estimation. By this we can conclude that this photovoltaic water pumping system using decoupling capacitor is more helpful as the battery releases more amount of flue gases and this can reduce the usage of batteries and it can reduce pollution. This can be further implemented using fuzzy logic controller or through artificial neural network. The further implementation can be done in the form of above-mentioned way. This can help a lot in the crop irrigation system and this system is very useful for the farmers and this can be applicable at various places where ever required and this hard ware simulation can be done if there is proper place to accomplish it.

\section{REFERENCES}

1. United Nations, "World's population increasingly urban with more than half living in urban areas," [Online]. Available: www.un.org/en/development/desa/news/population/world-urbanizatio n-prospects-2014, 2014, [Accessed Mar. 2, 2018].

2. The Guardian, "Cities in numbers: how patterns of urban growth change the world," [Online]. Available: www.theguardian.com/cities/2015/nov/

23/cities-in-numbers-how-patterns-of-urban-growth-change-the-worl d, 2015, [ Accessed Mar. 2, 2018].

3. World Bank, "Rural population (\% of total population)," [Online]. Available: data. worldbank. Org /indicator /SP.RUR.TOTL.ZS, 2016, [Accessed Mar. 2, 2018].

4. F. Palmiro, J. O. P. Pinto, L. H. Pereira, and R. B. Godoy, "Cost-effective photovoltaic water pumping system for remote regions communities," in Energy Conversion Congress and Exposition (ECCE), 2014 IEEE. IEEE, 2014, pp. 3287-3293.

5. M. Arriaga, C. A. Ca nnizares, and M. Kazerani, "Renewable energy alternatives for remote communities in Northern Ontario, Canada," IEEE Transactions on Sustainable Energy, vol. 4, no. 3, pp. 661-670, 2013.

6. MKanagawa and T. Nakata, "Assessment of accessto electricity and the socio-economic impacts in rural areas of developing countries,' Energy Policy, vol. 36, no. 6, pp. 2016-2029, 2008.

7. A. Mazur, "Does increasing energy or electricity consumption improve quality of life in industrial nations?" Energy Policy, vol. 39, no. 5, pp. 2568-2572, 2011.

8. B.A. Bridge, D. Adhikari, and M. Fontenla, "Electricity, income, and quality of life," The Social Science Journal, vol. 53, no. 1, pp. 33-39, 2016.

9. World Health Organization and UniCeF, Progress on sanitation and drinking water: 2014 update. World Health Organization, 2014.

10. Divya, V., Sree, Y.A.N., Rajasekhar, S.," Reduction of torque ripple in 3 phase SRM drive using hybrid (Intelligent) controller" International Journal of Applied Engineering Research,vol.12(Special Issue 1), pp. 447-453, 2017

11. Sudharshan T, Naga Chaitanya M, Pakkiaraiah B, “ Design and Cost Benefit Analaysis of Standalone Photovoltaic System in Krishna Milk Union”, International Journal of Innovative technology and Exploring Engineering, ISSN: 2278-3075, Volume-8, Issue-6, April 2019.

12. B RamaKrishna, $\mathrm{T}$ Srikanth, M Naga Chaitanya, T Vijaymuni, "Comparitive Analysis of Pertub and Observe Method and Current Based Method", International Journal of Innovative technology and Exploring Engineering, ISSN: 2278-3075, Volume-8, Issue-6, April 2019.

13. Muni,T.V., Lalitha,S.V.N.L.,Suma,.K., Venkateswaramma, B. "A new approach to achieve a fast acting MPPT technique for solar photovoltaic system under fast varying solar radiation" International Journal of Engineering and Technology(UAE), 2019.

14. Srikanth M., Upadhyay P., Tara Kalyani S. "Single phase grid connected bi-directional inverter fed photovoltaic system for constant DC load", Journal of Advanced Research in Dynamical and Control Systems, 2019.

15. Raja sekhar G.G., Banakara B. "Photo-voltaic system fed high voltage gain DC-DC converter feeding BLDC drive with simplified speed control", ARPN Journal of Engineering and Applied Sciences, 2018.

16. Sunanda E, Divya Spandana, G Swapna, "Islanding detection for grid connected photovoltaic system for excess geeration and under generation", International Journal of Engineering \& technology, 2018

17. Muni, T.V., Lalitha, S.V.N.L. "Power management strategy in solar pv system with battery protection scheme in dc microgrid", International Journal of Innovative Technology and Exploring Engineering, 2019.

18. Ravi Teja, S., Moulali, S., Nikhil, M., Ventaka Srinivas, B. "A dual wireless power transfer-based battery charging system for electric vehicles", International Journal of Engineering and Advanced Technology, Volume 8, Issue 4, April 2019, Pages 1211-1214. 
Decoupling Capacitance Enabled Water Pumping System using Photovoltaic System

19. Mule Sai Krishna Reddy, D. Elangovan, "Control of BLDC Motor Air Cooler for Low Voltage DC House", International Journal of Innovative Technology and Exploring Engineering, 2019.

20. Suresh Palla, Jarupula Somlal, "Comprehensive Examination on Solar -Wind Energy Systems Grid Integration and Emerging Power Quality challenges", International Journal of Engineering and Advanced Technology (IJEAT) ISSN: 2249 - 8958, Volume-8, Issue-6S3, September 2019.

\section{AUTHORS PROFILE}

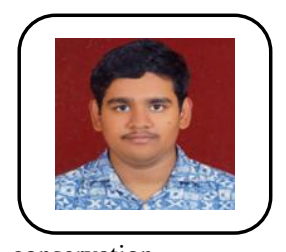

conservation.
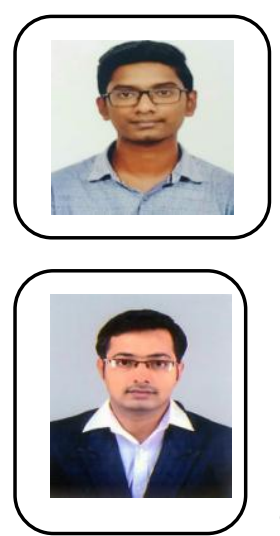
and guided more than 27 innovative projects as a part of his academic work. His research interests are Vijayawada Andhra Pradesh, India. He is studying final year B-Tech in department of Electrical and Electronics Engineering With specialization in energy systems in $\mathrm{K} \mathrm{L}$ deemed University, Green fields, Vaddeswaram, Guntur. His research of area is under Energy saving and

Adithya Sesha Sai krishna has been Studying in Electrical and Electronics Engineering with Specialization in Energy Systems for over 3 years. He is a Student at K L deemed to be university, Guntur. His Research focus on Energy Conservation and Energy saving

Sk. Moulali He is working as Assistant Professor in KLEF, Vaddeswaram, Guntur, Andhra Pradesh, India. He has received M. Tech degrees from Vignan University Guntur. He published 10 scopus and 10 international journal papers (non scopus). This author has overall 10 years teaching experience 